\title{
MAPEAMENTO E ANÁLISE DAS PRODUÇÕES CIENTÍFICAS QUE VERSAM SOBRE AS POLÍTICAS DE ASSISTÊNCIA ESTUDANTIL NO CONTEXTO DO PROGRAMA NACIONAL DE ASSISTÊNCIA ESTUDANTIL
}

\author{
MAPEO Y ANÁLISIS DE PRODUCCIONES CIENTÍFICAS QUE VERSAN EN \\ POLÍTICAS DE ASISTENCIA ESTUDIANTIL EN EL CONTEXTO DEL PROGRAMA \\ NACIONAL DE ASISTENCIA ESTUDIANTIL
}

\section{MAPPING AND ANALYSIS OF SCIENTIFIC PRODUCTIONS THAT VERSE STUDENT ASSISTANCE POLICIES IN THE CONTEXT OF THE NATIONAL STUDENT ASSISTANCE PROGRAM}

Adão Rogério Xavier Silva ${ }^{1}$ http://orcid.org/0000-0003-0277-3392

Mark Clark Assen de Carvalho ${ }^{2}$ http://orcid.org/0000-0003-3638-9719

Rafael Marques Gonçalves 3 http://orcid.org/0000-0002-9038-1542

\begin{abstract}
Resumo
Este artigo tem como objetivo mapear e analisar as produções científicas publicadas em teses e dissertações que versam sobre a temática das Políticas de Assistência Estudantil (PAE) no contexto do Programa Nacional de Assistência Estudantil (Pnaes). Busca-se compreender de que forma essa temática vem sendo discutida no campo analítico da Educação e de que maneira vem se dando a materialização dessa política nas Instituições de Educação Superior (IES), considerando os ambientes das universidades públicas federais e dos Institutos Federais de Educação, Ciência e Tecnologia (Ifes). Em termos de aportes teóricos para análise da PAE, o estudo apoia-se em Kowalski (2012) e Nascimento (2012). Metodologicamente, a pesquisa analisa o conteúdo da produção científica restrita à análise dos resumos e palavras-chaves, cujos objetos de estudo são as teses e dissertações disponíveis no Catálogo de Teses e Dissertações da Coordenação de Aperfeiçoamento de Pessoal de Nível Superior (Capes) publicadas entre os anos de 2013 e 2019.

\footnotetext{
${ }^{1}$ Mestre em Educação. Professor Substituto da Universidade Federal do Acre (UFAC), vinculado ao Centro de Educação Letras e Artes (CELA). E-mail: adaorxs@gmail.com

${ }^{2}$ Doutor em Educação. Professor Titular do Centro de Educação, Letras e Artes da Universidade Federal do Acre/UFAC e Professor Permanente do Programa de Pós-Graduação em Educação da UFAC e do Doutorado em Rede/EDUCANORTE. E-mail: markassen@yahoo.com.br

3 Doutor em Educação. Professor da Universidade Federal do Acre vinculado ao Programa de Pós-Graduação em Educação PPGE/UFAC. E-mail: rafamgo2@gmail.com
}

Como referenciar este artigo:

SILVA, A.R.X.; CARVALHO, M. C. A.; GONÇALVES, R. M. Mapeamento e análise das produções científicas que versam sobre as políticas de assistência estudantil no contexto do programa nacional de assistência estudantil. Revista Pedagógica, v. 23, p. 1-30, 2021. 


\title{
Revista do Programa de Pós-Graduação em Educação da Unochapecó ISSN 1984-1566 (on-line) ISSN 1415-8175 (impressa)
}

Como resultado, aponta-se o mapeamento de 36 produções, sendo 32 dissertações e 04 teses. No que se refere à análise das publicações, conclui-se que, em maior ou menor medida, a PAE assumese como paradoxal, pois ora manifesta-se inerente à Política de Assistência Social em uma perspectiva de inclusão/exclusão, ora como uma extensão desta. Em outros casos, procura atender à necessidade de sobrevivência, bem como a outras que ultrapassam essas condições. Contudo, não se pode negar a importância da Política de Assistência Estudantil em face do Pnaes, visto que, no período estudado, esta representa um significativo avanço em termos de condições de acesso e permanência no Ensino Superior brasileiro.

Palavras-chave: Produção científica. Assistência estudantil. Educação Superior. Pnaes

\section{Resumen}

Este artículo tiene como objetivo mapear y analizar las producciones científicas publicadas en tesis y disertaciones que abordan la temática de Políticas de Atención al Estudiante (PAE) en el contexto del Programa Nacional de Atención al Estudiante (Pnaes). Se busca comprender cómo se ha discutido este tema en el campo analítico de la Educación y cómo esta política se ha materializado en las Instituciones de Educación Superior (IES), considerando los entornos de las universidades públicas federales y los Institutos Federales de Educación, Ciencia y Tecnología (Ifes). En cuanto a las contribuciones teóricas al análisis de PAE, el estudio es apoyado por Kowalski (2012) y Nascimento (2012). Metodológicamente, la investigación analiza el contenido de la producción científica restringida al análisis de resúmenes y palabras clave, cuyos objetos de estudio son las tesis y disertaciones disponibles en el Catálogo de Tesis y Disertaciones de la Coordinación para la Perfeccionamiento del Personal de Educación Superior (Capes) publicado entre los años 2013 y 2019. Como resultado, se apunta el mapeo de 36 producciones, con 32 tesis de maestría y 04 tesis doctorales. En cuanto al análisis de las publicaciones, se concluye que, en mayor o menor medida, se asume que el PAE es paradójico, ya que se manifiesta inherente a la Política Asistencial en una perspectiva de inclusión/exclusión, en ocasiones como extensión de esto. En otros casos, busca satisfacer la necesidad de supervivencia, así como otros que van más allá de estas condiciones. Sin embargo, no se puede negar la importancia de la Política de Asistencia al Estudiante frente a la Pnaes, ya que, durante el período estudiado, representa un avance significativo en términos de condiciones de acceso y permanencia en la Educación Superior brasileña.

Palabras clave: Producción científica. Asistencia al estudiante. Educación universitaria. Pnaes.

\begin{abstract}
This article aims to map and analyze the scientific productions published in theses and dissertations that deal with the theme of Student Assistance Policies (PAE) in the context of the National Student Assistance Program (Pnaes). It seeks to understand how this theme has been discussed in the analytical field of Education and how this policy has materialized in Higher Education Institutions (HEls), considering the environments of federal public universities and Federal Institutes of Education , Science and Technology (Ifes). In terms of theoretical contributions to the analysis of PAE, the study is supported by Kowalski (2012) and Nascimento (2012). Methodologically, the research analyzes the content of scientific production restricted to the analysis of abstracts and keywords, whose objects of study are the theses and dissertations available in the Catalog of Theses and Dissertations of the Coordination for the Improvement of Higher Education Personnel (Capes) published between the years 2013 and 2019. As a result, the mapping of 36 productions is pointed out, with 32 dissertations and 04 theses. With regard to the analysis of publications, it is concluded that, to a greater or lesser extent, the PAE is assumed to be paradoxical, since it is manifested inherent to the Social Assistance Policy in an inclusion/exclusion perspective, now as
\end{abstract}


extension of this. In other cases, it seeks to meet the need for survival, as well as others that go beyond these conditions. However, it cannot be denied the importance of the Student Assistance Policy vis-à-vis the Pnaes, since, during the studied period, it represents a significant advance in terms of access and permanence conditions in Brazilian Higher Education.

Keywords: Scientific production. Student assistance. College education. Pnaes.

\section{INTRODUÇÃO}

Em concordância com Kowalski (2012), os processos históricos de formalização da assistência estudantil como uma política pública da Educação Superior no Brasil estão postos em três fases distintas, conjugadas ao cenário das políticas públicas educacionais do país, sublinhado por movimentos complexos, conflituosos e dinâmicos.

A primeira fase corresponde ao período da criação da Casa do Estudante Brasileiro, em 1928, e estende-se até o final da década de 1970, quando se tem a criação do Departamento de Assistência ao Estudante (DAE); a segunda fase condiz com o período próximo à abertura democrática no Brasil, especificamente, a partir da criação do Fórum Nacional de Pró-Reitores de Assuntos Comunitários e Estudantis (Fonaprace), em 1987, e amplifica-se até a elaboração do Programa Universidade para Todos (ProUni), nos anos de 2004. A terceira fase corresponde ao período que se inicia em 2007, a contar da criação do Programa de Apoio a Planos de Reestruturação e Expansão das Universidades Federais (Reuni) e estende-se até os dias atuais (KOWALSKI, 2012).

O presente artigo inscreve-se em uma análise pautada especificamente na terceira fase, uma vez que o objetivo principal da análise foi a de mapear e analisar a constituição da Política de Assistência Estudantil (PAE) no contexto do Programa Nacional de Assistência Estudantil (PNAES), cuja fonte é o Catálogo de Teses e Dissertações da Coordenação de Aperfeiçoamento de Pessoal de Nível Superior (CAPES), publicadas no período de 2013 a 2019. Para tanto, foram sistematizadas e analisadas as produções científicas na área da educação, ou seja, o mapeamento de 36 produtos, sendo 32 dissertações e 04 teses, referenciando-se a análise na leitura dos resumos e palavras-chave.

O estudo está assim estruturado: a primeira seção apresenta breves considerações sobre a natureza do Pnaes, a fim de possibilitar uma compreensão a respeito dessa política pública no âmbito da Educação Superior. Na sequência, apresenta as delimitações 
metodológicas empreendidas para efetivação do mapeamento do objeto de estudo perseguido - as teses e dissertações produzidas na área de educação no período de 2013 a 2019. Na terceira seção, estão dispostos elementos da análise do conteúdo veiculado nas produções selecionadas, tendo como indexadores os títulos, resumos e palavras-chave.

\section{BREVES APONTAMENTOS SOBRE O PNAES}

Criado com objetivo de combater as desigualdades sociais e regionais, bem como visando à ampliação e democratização das condições de acesso e permanência dos estudantes das Instituições de Educação Superior (IES), o Programa Nacional de Assistência Estudantil (PNAES) foi instituído em 12 de dezembro de 2007 pela Portaria Normativa $n^{\circ} 39$ do Ministério da Educação e Cultura (MEC). Sua implementação ocorreu no ano de 2008 , conforme previa o Art. $6^{\circ}$ da respectiva portaria.

Assim, na Lei Orçamentária Anual (LOA) da União para exercício financeiro de 2008, verificou-se a reserva de orçamento global na ordem de $\mathrm{R} \$ 126.301 .634,00$ (cento e vinte seis milhões, trezentos e um mil, seiscentos e trinta e quatro reais), alocado no programa 1073 - Brasil Universitário, na ação 4002 - Assistência ao Estudante do Ensino de Graduação. Ligada ao Pnaes, a assistência estudantil vincula-se ao desenvolvimento das atividades de ensino, pesquisa e extensão e é destinada aos estudantes de cursos de graduação presencial selecionados a partir de critérios socioeconômicos, conforme se explicita:

\footnotetext{
Art. $2^{\circ}[\ldots]$

Parágrafo único. Compreendem-se como ações de assistência estudantil iniciativas desenvolvidas nas seguintes áreas:

I - moradia estudantil; II - alimentação; III - transporte; IV - assistência à saúde; V inclusão digital; VI - cultura; VII - esporte; VIII - creche; e IX - apoio pedagógico (BRASIL, 2007).
}

O projeto que deu origem ao Pnaes resulta das contribuições do Fórum Nacional de Pró-Reitores de Assuntos Comunitários e Estudantis (Fonaprace), instituído nos anos de 1987, fruto dos Encontros Nacionais de Pró-Reitores de Assuntos Comunitários Estudantis e dos encontros realizados pela Associação Nacional dos Dirigentes das Instituições Federais de Ensino Superior (Andifes). No fórum, Pró-Reitores, Sub-Reitores, entre outros envolvidos com a coordenação, gestão e pesquisa dos assuntos comunitários e estudantis 
das IES, empenham-se no debate de pautas como: a relevância da assistência estudantil para manutenção da vida acadêmica e na democratização da universidade pública e gratuita frente ao acesso dos estudantes de baixa renda (KOWALSKI, 2012).

Em sua atuação destacam-se, especialmente, as pesquisas realizadas em âmbito nacional, nos anos de 1997 e 2004, para traçar o perfil socioeconômico e cultural dos estudantes de graduação das IES. Tais estudos possibilitaram diagnosticar a situação dos estudantes e traçar uma proposta fundamentada, de modo que o texto apresentado ao MEC veio a se tornar o Pnaes (FONAPRACE, 2008).

Nesse processo, observa-se em Costa (2010) e em Kowalski (2012) que a trajetória trilhada para a consolidação da assistência estudantil enquanto política pública de direito é marcada pela partição de atores coletivos. A título de exemplo, vale lembrar da contribuição do movimento estudantil nesse processo, cuja representatividade pode ser vislumbrada por meio da União Nacional do Estudantes (UNE), que, já nos idos de 1938, manifestou, no Plano de Reforma Educacional, a defesa do auxílio aos estudantes com dificuldades econômicas. Desse modo, o Pnaes representa a conquista da luta coletiva de grupos organizados, especialmente da Andifes, do Fonaprace e da UNE.

No ano de 2010, o Pnaes deixa o status de Portaria Normativa passando a ser Decreto-Lei $n^{\circ}$ 7.234, de 19 de julho de 2010. Em acordo com Paula (2017), é notável a importância da institucionalização em lei, posto que, a partir disso, o Governo Federal passou a se comprometer legalmente com a efetivação do repasse de recursos financeiros às universidades públicas e Institutos Federais.

Composto por nove artigos, o Decreto Lei $n^{\circ} 7.234 / 2010$ define a finalidade e os objetivos da política, conforme se verifica in verbis:

Art. $1^{\circ} \mathrm{O}$ Programa Nacional de Assistência Estudantil - PNAES, executado no âmbito do Ministério da Educação, tem como finalidade ampliar as condições de permanência dos jovens na educação superior pública federal e ampliar as condições de permanência dos jovens na educação superior pública federal.

Art. $2^{\circ}$ São objetivos do PNAES:

I - democratizar as condições de permanência dos jovens na educação superior pública federal; II - minimizar os efeitos das desigualdades sociais e regionais na permanência e conclusão da educação superior; III - reduzir as taxas de retenção e evasão; e IV - contribuir para a promoção da inclusão social pela educação (BRASIL, 2010). 
Seja na forma de Portaria Normativa n 39, instituída em 12 de dezembro de 2007, seja na forma de Decreto-Lei $n^{\circ} 7.234$, de 19 julho de 2010, o Pnaes não foi elaborado e finalizado em seu momento legislativo. Isso posto, é importante ressaltar que seus textos se vinculam à conjuntura de tempo e espaço da sua produção, à historicidade dos movimentos basilares para sua escrita, às contradições, disputas e acordos em prol do controle de sua representação.

É importante não perder de vista que a sua institucionalização, enquanto política pública para efetivação das ações de assistência estudantil, não se constituiu repentinamente, a toque de uma assinatura seguida de uma publicação no diário oficial. Muito pelo contrário, as disputas de influência para a definição e finalidades da assistência estudantil preliminar ao Pnaes estiveram - e estão - sobrepostas ao contexto correlato ao período da segunda fase histórica da constituição da Política de Assistência Estudantil, iniciada nos anos de 1987 e, também, da terceira fase, estabelecida por volta do ano de 2007 e que se estende até os dias atuais.

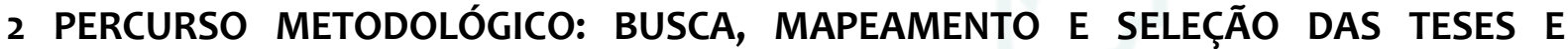 DISSERTAÇÕES}

O primeiro passo que se impôs para a definição metodológica dos caminhos da busca pautou-se na delimitação temporal do estudo e nos seguintes refinamentos:

a) Os últimos sete anos (2013 a 2019), visto que a base de dados disponível no Catálogo de Teses e Dissertações ${ }^{4}$ é vinculada aos documentos originários da base de dados da Plataforma Sucupira, que, por sua vez, disponibiliza dados a partir do ano de 2013;

b) Como filtro de pesquisa, considerou-se a demarcação apenas das produções científicas desenvolvidas no âmbito dos Programas de Pós-Graduação em Educação, sendo programas de doutorados e mestrados acadêmicos;

c) Leitura e análise dos resumos e das teses e dissertações;

d) Como palavras-chave, utilizou-se: “Assistência Estudantil” e "Pnaes”.

Cabe destacar que esse movimento de pesquisa na plataforma do Catálogo de Teses e Dissertações da Coordenação de Aperfeiçoamento de Pessoal de Nível Superior (Capes)

\footnotetext{
${ }^{4}$ https://catalogodeteses.capes.gov.br/catalogo-teses/\#!/
} 


\section{REVISTA}

\section{Revista do Programa de Pós-Graduação em Educação da Unochapecó ISSN 1984-1566 (on-line) ISSN 1415-8175 (impressa)}

ocorreu entre os meses de abril e maio do corrente ano. Assim, a partir dos indexadores definidos, obteve-se, como resultado preliminar, montante numericamente expressivo, apontando-se 581 ocorrências para a palavras-chave Assistência Estudantil e 20 para Pnaes, distribuídas anualmente, conforme constam nos Quadros 01 e 02 expostos a seguir:

Quadro 1 - Filtro da palavra-chave "assistência estudantil” por ano e quantidade de ocorrência

\begin{tabular}{|c|c|c|c|c|c|}
\hline $\begin{array}{c}\text { Palavras- } \\
\text { chave }\end{array}$ & $\begin{array}{c}\text { Filtro pelo } \\
\text { nome do } \\
\text { programa }\end{array}$ & Ano & $\begin{array}{c}\text { Resultados } \\
\text { encontrados }\end{array}$ & $\begin{array}{c}\text { Palavras-chave } \\
\text { correlatas com } \\
\text { outras temáticas }\end{array}$ & Resumos lidos \\
\hline \multirow{4}{*}{$\begin{array}{c}\text { Assistência } \\
\text { Estudantil }\end{array}$} & \multirow{4}{*}{ EDUCAÇÃO } & 2019 & 67 & 61 & 06 \\
\cline { 3 - 6 } & 2018 & 97 & 89 & 08 \\
\cline { 3 - 6 } & 2017 & 104 & 100 & 04 \\
\cline { 3 - 6 } & 2016 & 103 & 98 & 05 \\
\cline { 3 - 6 } & 2015 & 74 & 67 & 04 \\
\cline { 3 - 6 } & 2014 & 70 & 65 & 01 \\
\cline { 3 - 6 } & 2013 & 66 & 546 & 35 \\
\hline
\end{tabular}

Fonte: Catálogo de Teses e Dissertações da Capes. Quadro elaborado pelos autores (2020).

Quadro 2 - Filtro da palavra-chave "PNAES! por ano e quantidade de ocorrência

\begin{tabular}{|c|c|c|c|c|c|}
\hline \multirow{2}{*}{$\begin{array}{c}\text { Palavras- } \\
\text { chave }\end{array}$} & $\begin{array}{c}\text { Filtro pelo } \\
\text { nome do } \\
\text { programa }\end{array}$ & Ano & $\begin{array}{c}\text { Resultados } \\
\text { encontrados }\end{array}$ & $\begin{array}{c}\text { Palavras-chave } \\
\text { correlatas com } \\
\text { outras temáticas }\end{array}$ & Resumos lidos \\
\hline \multirow{4}{*}{ PNAES } & \multirow{4}{*}{ EDUCAÇÃO } & 2019 & 03 & $00 / 03^{5}$ & 00 \\
\cline { 3 - 6 } & 2018 & 06 & $01 / 05$ & 00 \\
\cline { 3 - 6 } & & 2017 & 02 & $01 / 01$ & 00 \\
\cline { 3 - 6 } & 2016 & 02 & $00 / 02$ & 01 \\
\cline { 3 - 6 } & 2015 & 04 & $00 / 04$ & 00 \\
\cline { 3 - 6 } & 2014 & 02 & $00 / 02$ & 00 \\
\hline & 2013 & 01 & $02 / 19$ & 01 \\
\hline
\end{tabular}

Fonte: Catálogo de Teses e Dissertações da Capes. Quadro elaborado pelos autores (2020).

$\mathrm{Na}$ análise dos resultados encontrados percebeu-se, inicialmente, com base nos títulos e palavras-chave de algumas das pesquisas, um certo distanciamento da temática pesquisada, ou seja, ainda que essas pesquisas tenham sido filtradas pelas palavras-chave “Assistência Estudantil” e "Pnaes”, elas não indicavam correlação direta com a Política de

\footnotetext{
${ }^{5}$ Os números à esquerda da barra representam os estudos descartados dada a desconexão com a temática. Já os números à direita da barra correspondem aos estudos que possuem vínculo com a temática. Contudo, somente uma pesquisa do ano de 2016 teve seu resumo lido, pois as demais listadas já haviam sido encontradas e lidas a partir da palavra-chave Assistência Estudantil.
} 
Assistência Estudantil no âmbito do Pnaes. Como exemplo, têm-se as pesquisas que apresentavam as seguintes palavras-chave: Movimento Estudantil; Migração Estudantil Internacional; Juventude universitária; Políticas Públicas de distribuição de livros; Privatização e Financeirização; Programa Mais Educação, entre outras. Tais pesquisas aparecem numericamente nos quadros expostos acima, na coluna "Palavras-chave correlatas com outras temáticas".

Diante desse cenário indicado pelos dados gerais, optou-se por descartar da análise pretendida um quantitativo de 546 estudos encontrados a partir da palavra-chave Assistência Estudantil e 02 a partir da palavra-chave Pnaes. Sinaliza-se que essa opção de seleção empreendida não teve a intenção de engavetar os dados excluídos como sendo irrelevantes para o conhecimento científico no campo da Educação, tratou-se tão somente de uma opção metodológica por considerá-los por demais distanciados da temática pesquisada e do objetivo proposto no estudo.

No tocante à palavra-chave Pnaes, quase todos os resultados encontrados já haviam sido listados nos resultados de busca da palavra-chave Assistência Estudantil, com exceção da pesquisa de Nóbrega (2016). Desse modo, elaborou-se o Quadro 03, síntese do mapeamento da temática Política de Assistência Estudantil no âmbito do Pnaes, com base no Catálogo de Teses e Dissertações da Capes, contendo 36 estudos, sendo: 32 dissertações e 04 teses.

Quadro 3 - Mapeamento de teses e dissertações de acordo com a temática política de assistência estudantil no âmbito do PNAES - 2013 a 2019 (continua)

\begin{tabular}{|l|l|l|l|}
\hline Ano & \multicolumn{1}{|c|}{ Autor (a) } & \multicolumn{1}{|c|}{ Título } & \multicolumn{1}{|c|}{ Programa/IES } \\
\hline \multirow{2}{*}{2019} & $\begin{array}{l}\text { CAMENIETZKI, } \\
\text { Carolina Poswar de } \\
\text { Araújo }\end{array}$ & $\begin{array}{l}\text { Interfaces entre a Assistência } \\
\text { Estudantil e a Assistência Social: a } \\
\text { concepção de assistência em } \\
\text { construção na UFMG }\end{array}$ & $\begin{array}{l}\text { Programa de Pós- } \\
\text { Graduação em } \\
\text { Educação da } \\
\text { Universidade Federal } \\
\text { de Uberlândia }\end{array}$ \\
\cline { 2 - 4 } & $\begin{array}{l}\text { GOMEZ, Magela Reny } \\
\text { Fonticiella }\end{array}$ & $\begin{array}{l}\text { Políticas de permanência estudantil na na de Pós- } \\
\text { educação superior contemporânea: a } \\
\text { experiência da UTFPR - Câmpus } \\
\text { Medianeira }\end{array}$ & $\begin{array}{l}\text { Educação da } \\
\text { Faculdade de Filosofia } \\
\text { e Ciências da } \\
\text { Universidade Estadual } \\
\text { Paulista - Campus de } \\
\text { Marília, SP }\end{array}$ \\
\hline
\end{tabular}




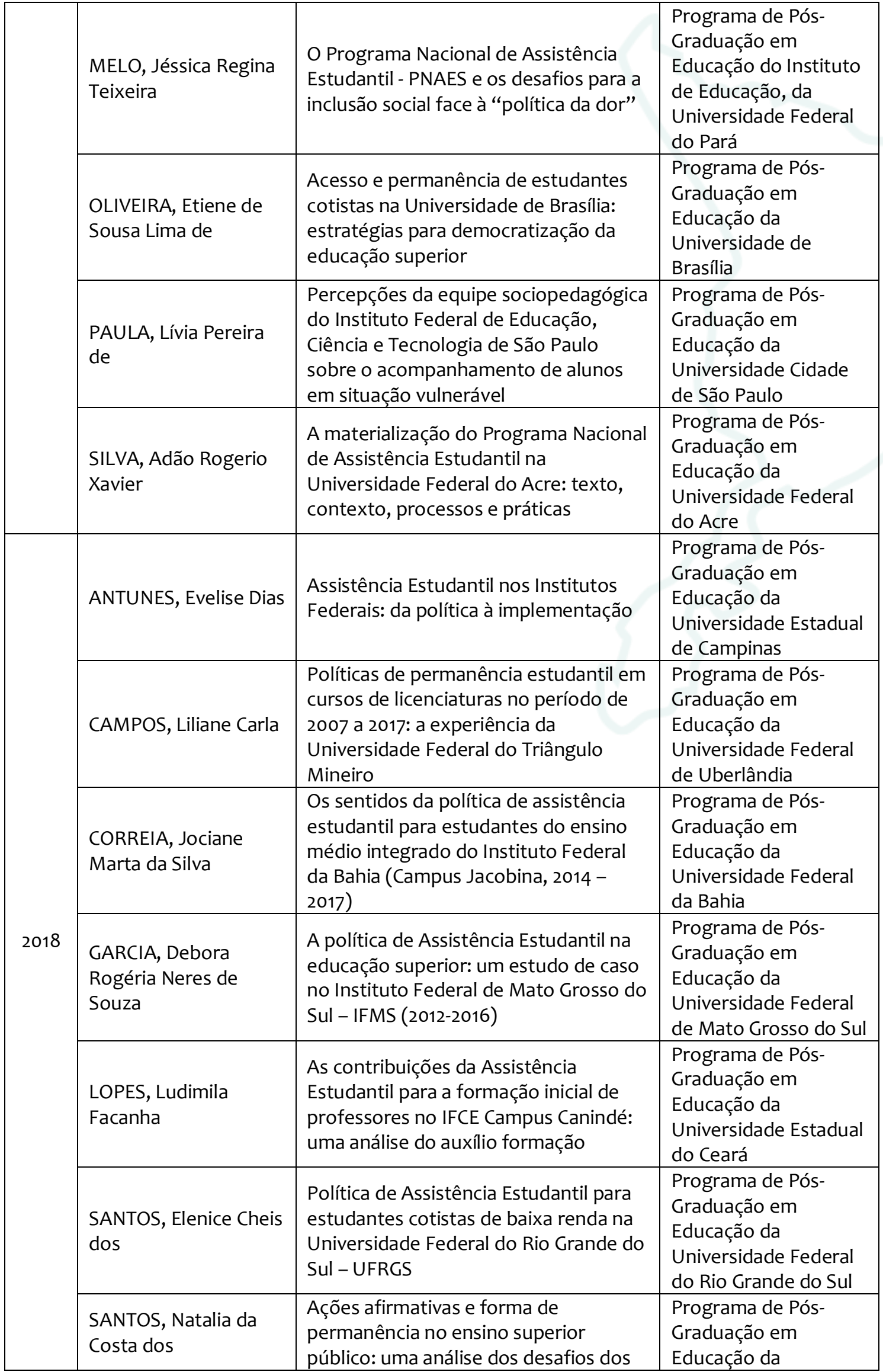


Revista do Programa de Pós-Graduação em Educação da Unochapecó ISSN 1984-1566 (on-line) ISSN 1415-8175 (impressa)

\begin{tabular}{|l|l|l|l|}
\hline & $\begin{array}{l}\text { profissionais na execução da } \\
\text { assistência estudantil da UFF }\end{array}$ & $\begin{array}{l}\text { Universidade Federal } \\
\text { Fluminense }\end{array}$ \\
\cline { 2 - 4 } & $\begin{array}{l}\text { O programa de auxílio permanência, da } \\
\text { política de Assistência Estudantil no } \\
\text { SILVA, Ana Rita } \\
\text { Dantas da }\end{array}$ & $\begin{array}{l}\text { Programa de Pós- } \\
\text { Grofissional e tecnológica: um estudo } \\
\text { Go Progano em } \\
\text { São Paulo }\end{array}$ & $\begin{array}{l}\text { Educação da } \\
\text { Universidade Cidade } \\
\text { de São Paulo }\end{array}$ \\
\hline
\end{tabular}

Fonte: Catálogo de Teses e Dissertações da Capes. Quadro elaborado pelos autores (2020).

Quadro 3-Mapeamento de teses e dissertações de acordo com a temática política de assistência estudantil no âmbito do PNAES - 2013 a 2019 (continua)

\begin{tabular}{|c|c|c|c|}
\hline \multirow{4}{*}{2017} & GIMENEZ, Felipe Vieira & $\begin{array}{l}\text { Expansão e inclusão na educação } \\
\text { superior: a bolsa permanência na } \\
\text { UFMS }\end{array}$ & $\begin{array}{l}\text { Programa de Pós- } \\
\text { Graduação em } \\
\text { Educação do Campus } \\
\text { Campo Grande da } \\
\text { Universidade Federal } \\
\text { de Mato Grosso do Sul }\end{array}$ \\
\hline & MOTTA, Thalita Cunha & $\begin{array}{l}\text { Assistência estudantil e inclusão social: } \\
\text { mudanças discursivas e } \\
\text { recontextualização no caso do IFRN }\end{array}$ & $\begin{array}{l}\text { Programa de Pós- } \\
\text { Graduação em } \\
\text { Educação da } \\
\text { Universidade Federal } \\
\text { de Pernambuco }\end{array}$ \\
\hline & $\begin{array}{l}\text { SANTOS, Fernando } \\
\text { Nunes dos }\end{array}$ & $\begin{array}{l}\text { As percepções dos sujeitos que } \\
\text { vivenciam a assistência estudantil } \\
\text { acerca desse direito social: um olhar a } \\
\text { partir do IFNMG, Campus Avançado } \\
\text { Janaúba }\end{array}$ & $\begin{array}{l}\text { Programa de Pós- } \\
\text { Graduação em } \\
\text { Educação da } \\
\text { Universidade Estadual } \\
\text { do Sudoeste da Bahia }\end{array}$ \\
\hline & $\begin{array}{l}\text { SILVEIRA, Antônia } \\
\text { Vanessa Freitas }\end{array}$ & $\begin{array}{l}\text { A Assistência Estudantil na UFPA e as } \\
\text { repercussões para os discentes do } \\
\text { curso de pedagogia: da permanência à } \\
\text { conclusão }\end{array}$ & $\begin{array}{l}\text { Programa de Pós- } \\
\text { Graduação em } \\
\text { Educação do Instituto } \\
\text { de Ciências da } \\
\text { Educação da } \\
\text { Universidade Federal } \\
\text { do Pará }\end{array}$ \\
\hline \multirow{4}{*}{2016} & LEAL, Elisiene Borges & $\begin{array}{l}\text { Vozes afrodescendentes: o que alguns } \\
\text { (mas) estudantes da Universidade } \\
\text { Federal do Piauí contam sobre a } \\
\text { assistência estudantil? }\end{array}$ & $\begin{array}{l}\text { Programa de Pós- } \\
\text { Graduação em } \\
\text { Educação da } \\
\text { Universidade Federal } \\
\text { do Piauí }\end{array}$ \\
\hline & $\begin{array}{l}\text { NÓBREGA, Evangelita } \\
\text { Carvalho da }\end{array}$ & $\begin{array}{l}\text { Ações Afirmativas na Universidade } \\
\text { Popular Brasileira: O Caso da } \\
\text { Universidade Federal do Sul da Bahia }\end{array}$ & $\begin{array}{l}\text { Programa de Pós- } \\
\text { Graduação em } \\
\text { Educação da } \\
\text { Universidade Nove de } \\
\text { Julho }\end{array}$ \\
\hline & $\begin{array}{l}\text { NUNES, Roseli Souza } \\
\text { dos Reis }\end{array}$ & $\begin{array}{l}\text { A permanência dos estudantes que } \\
\text { ingressaram por ação afirmativa: a } \\
\text { Assistência Estudantil em foco }\end{array}$ & $\begin{array}{l}\text { Programa de Pós- } \\
\text { Graduação em } \\
\text { Educação da } \\
\text { Universidade Federal } \\
\text { de Mato Grosso }\end{array}$ \\
\hline & $\begin{array}{l}\text { SOUZA, Daniele } \\
\text { Graciane de }\end{array}$ & $\begin{array}{l}\text { Acesso e permanência na UFPR: uma } \\
\text { análise da Política de Assistência } \\
\text { Estudantil (2010 - } 2014\end{array}$ & $\begin{array}{l}\text { Programa de Pós- } \\
\text { Graduação em } \\
\text { Educação da }\end{array}$ \\
\hline
\end{tabular}




\begin{tabular}{|c|c|c|c|}
\hline & & & $\begin{array}{l}\text { Universidade Federal } \\
\text { do Paraná }\end{array}$ \\
\hline & SPRICIGO, Fabricio & $\begin{array}{l}\text { A assistência estudantil no Instituto } \\
\text { Federal de Educação, Ciência e } \\
\text { Tecnologia de Santa Catarina: em } \\
\text { análise o Programa de Atendimento ao } \\
\text { Estudante em Vulnerabilidade Social }\end{array}$ & $\begin{array}{l}\text { Programa de Pós- } \\
\text { Graduação em } \\
\text { Educação da } \\
\text { Universidade do } \\
\text { Estado de Santa } \\
\text { Catarina }\end{array}$ \\
\hline & $\begin{array}{l}\text { TEIXEIRA, Luciana de } \\
\text { Gois Aquino }\end{array}$ & $\begin{array}{l}\text { Políticas públicas de Assistência } \\
\text { Estudantil no Instituto Federal Goiano } \\
\text { - Câmpus Urutaí: um olhar de gênero. }\end{array}$ & $\begin{array}{l}\text { Programa de Pós- } \\
\text { Graduação Stricto } \\
\text { sensu em Educação da } \\
\text { Pontifícia } \\
\text { Universidade Católica } \\
\text { de Goiás }\end{array}$ \\
\hline \multirow{6}{*}{2015} & $\begin{array}{l}\text { BAQUEIRO, Diciola } \\
\text { Figueiredo de } \\
\text { Andrade }\end{array}$ & $\begin{array}{l}\text { Equidade e eficácia na educação: } \\
\text { contribuições da Política de Assistência } \\
\text { Estudantil na permanência e } \\
\text { desempenho discente }\end{array}$ & $\begin{array}{l}\text { Programa de Pós- } \\
\text { graduação da } \\
\text { Faculdade de } \\
\text { Educação da } \\
\text { Universidade Federal } \\
\text { da Bahia }\end{array}$ \\
\hline & $\begin{array}{l}\text { BETZEK, Simone } \\
\text { Beatris Farinon }\end{array}$ & $\begin{array}{l}\text { Avaliação do Programa Nacional de } \\
\text { Assistência Estudantil - PNAES na } \\
\text { UTFPR Câmpus Medianeira }\end{array}$ & $\begin{array}{l}\text { Programa de Pós- } \\
\text { Graduação em } \\
\text { Educação da } \\
\text { Faculdade de Filosofia } \\
\text { e Ciências da } \\
\text { Universidade Estadual } \\
\text { Paulista }\end{array}$ \\
\hline & FILHO, Izaias Costa & $\begin{array}{l}\text { Políticas de assistência ao estudante: } \\
\text { formulação e implementação no } \\
\text { Instituto Federal do Paraná (2008- } \\
\text { 2014) }\end{array}$ & $\begin{array}{l}\text { Programa de Pós- } \\
\text { Graduação Mestrado } \\
\text { e Doutorado em } \\
\text { Educação da } \\
\text { Universidade Tuiuti do } \\
\text { Paraná }\end{array}$ \\
\hline & LOEBLIN, Elaine Lucio & $\begin{array}{l}\text { A materialização do Programa Nacional } \\
\text { de Assistência Estudantil PNAES para } \\
\text { estudantes de graduação da UNIR/ Ji- } \\
\text { paraná/RO }\end{array}$ & $\begin{array}{l}\text { Programa de Pós- } \\
\text { Graduação em } \\
\text { Educação da } \\
\text { Universidade Federal } \\
\text { de Mato Grosso } \\
\text { Universidade Federal } \\
\text { de Rondônia }\end{array}$ \\
\hline & $\begin{array}{l}\text { MACEDO, Livia } \\
\text { Fernanda Leal }\end{array}$ & $\begin{array}{l}\text { O auxílio de formação profissional do } \\
\text { Instituto Federal de Educação, Ciência } \\
\text { e Tecnologia do Tocantins - campus } \\
\text { Palmas: a Assistência Estudantil em } \\
\text { xeque }\end{array}$ & $\begin{array}{l}\text { Programa de Pós- } \\
\text { Graduação em } \\
\text { Educação da } \\
\text { Universidade Federal } \\
\text { de Santa Maria }\end{array}$ \\
\hline & $\begin{array}{l}\text { MENDONCA, Gisela de } \\
\text { Barros Alves }\end{array}$ & $\begin{array}{l}\text { O princípio da gratuidade ativa no } \\
\text { Programa de Assistência Estudantil do } \\
\text { Instituto Federal de Educação, Ciência } \\
\text { e Tecnologia de São Paulo (IFSP) - } \\
\text { campus Cubatão }\end{array}$ & $\begin{array}{l}\text { Programa de Pós- } \\
\text { Graduação em } \\
\text { Educação da } \\
\text { Universidade } \\
\text { Metodista de São } \\
\text { Paulo }\end{array}$ \\
\hline
\end{tabular}

Fonte: Catálogo de Teses e Dissertações da Capes. Quadro elaborado pelos autores (2020). 
Revista do Programa de Pós-Graduação em Educação da Unochapecó ISSN 1984-1566 (on-line) ISSN 1415-8175 (impressa)

Quadro 3 - Mapeamento de teses e dissertações de acordo com a temática política de assistência estudantil no âmbito do PNAES - 2013 a 2019 (conclusão)

\begin{tabular}{|c|c|c|c|}
\hline \multirow{5}{*}{2014} & $\begin{array}{l}\text { PRIMÃO, Juliana } \\
\text { Cristina Magnani }\end{array}$ & $\begin{array}{l}\text { Permanência na educação superior } \\
\text { pública: o curso de enfermagem da } \\
\text { Universidade Federal de Mato Grosso, } \\
\text { Campus universitário de Sinop }\end{array}$ & $\begin{array}{l}\text { Programa de Pós- } \\
\text { Graduação em } \\
\text { Educação da } \\
\text { Universidade Federal } \\
\text { de Mato Grosso }\end{array}$ \\
\hline & STOLF, Franciele & $\begin{array}{l}\text { Assistência estudantil na Universidade } \\
\text { Federal de Santa Catarina: uma análise } \\
\text { inicial do programa bolsa estudantil }\end{array}$ & $\begin{array}{l}\text { Programa de Pós- } \\
\text { Graduação em } \\
\text { Educação da } \\
\text { Universidade Federal } \\
\text { de Santa Catarina }\end{array}$ \\
\hline & PALAVEZZINI, Juliana & $\begin{array}{l}\text { Os programas de assistência estudantil } \\
\text { do ensino superior no Brasil: a } \\
\text { experiência da UTFPR-dois vizinhos }\end{array}$ & $\begin{array}{l}\text { Programa de Pós- } \\
\text { graduação em } \\
\text { Sociedade, Estado e } \\
\text { Educação da } \\
\text { Universidade Estado } \\
\text { do Oeste do Paraná }\end{array}$ \\
\hline & $\begin{array}{l}\text { SANTIAGO, Salomão } \\
\text { Nunes }\end{array}$ & $\begin{array}{l}\text { A política de assistência estudantil no } \\
\text { governo Lula: } 2003 \text { a } 2010\end{array}$ & $\begin{array}{l}\text { Programa de Pós- } \\
\text { Graduação em } \\
\text { Educação, do Instituto } \\
\text { de Ciências da } \\
\text { Educação da } \\
\text { Universidade Federal } \\
\text { do Pará }\end{array}$ \\
\hline & $\begin{array}{l}\text { OLIVEIRA, Marcia } \\
\text { Pereira de }\end{array}$ & $\begin{array}{l}\text { Ditos e não ditos: como se constitui o } \\
\text { sujeito bolsista imerso na política de } \\
\text { assistência estudantil (2009-2013) }\end{array}$ & $\begin{array}{l}\text { Programa de Pós- } \\
\text { Graduação em } \\
\text { Educação da } \\
\text { Universidade do Vale } \\
\text { do Rio dos Sinos }\end{array}$ \\
\hline 2013 & $\begin{array}{l}\text { RADAELLI, Andressa } \\
\text { Benvenutti }\end{array}$ & $\begin{array}{l}\text { Permanência na Educação Superior: } \\
\text { uma análise das Políticas de Assistência } \\
\text { Estudantil na Universidade Federal da } \\
\text { Fronteira Sul }\end{array}$ & $\begin{array}{l}\text { Programa de Pós- } \\
\text { Graduação em } \\
\text { Educação da } \\
\text { Universidade Estadual } \\
\text { do Oeste do Paraná }\end{array}$ \\
\hline
\end{tabular}

Fonte: Catálogo de Teses e Dissertações da Capes. Quadro elaborado pelos autores (2020).

Antes de se efetivar uma leitura atenciosa dos estudos mapeados e sistematizadas no Quadro 3, buscou-se verificar a pertinência dos resultados. Para tanto, examinou os títulos e as palavras-chave utilizadas nas pesquisas encontradas.

Conforme a Associação Brasileira de Normas e Técnicas (ABNT), o título corresponde à "palavra, expressão ou frase que designa o assunto ou o conteúdo de uma publicação" (ABNT, 2003, p. 02). Assim, o passo seguinte foi o de verificar a sintetização do conteúdo pelos títulos, de modo a garantir a coerência dos resultados encontrados com a temática Política de Assistência Estudantil no âmbito do Pnaes. 
Após análise feita nos títulos, percebeu-se a intencionalidade de delimitação e especificação da Política de Assistência Estudantil, considerando-a no âmbito da sua implementação, repercussão, desafios, contribuição, percepção e avaliação, na educação superior - nas Instituição de Ensino Superior e Institutos Federais -, assim como foram observadas questões consoantes às ações afirmativas, expansão, inclusão e permanência. Desse modo, o exercício da análise dos títulos, em aspectos gerais, permitiu a certificação destes quanto à harmonia com a temática em questão.

A palavra-chave é a "palavra representativa do conteúdo do documento, escolhida em vocabulário controlado" (ABNT, 2003, p. 02), ou ainda, conforme Houaiss (2001), citado por Lima Gonçalves (2008), é a palavra que traduz o sentido de um contexto, ou seja, busca torná-lo mais claro e o identifica. Também pode ser compreendida como a que identifica elementos relacionados ou que pertencem à mesma área de interesse da pesquisa.

Hartley e Kostoff (2003) indicam que as palavras-chave, quando utilizadas nas bases de dados especializadas para a divulgação científica:

\footnotetext{
1. permitem que os leitores decidam se um artigo possui ou não material relevante de acordo com seus interesses;

2. fornecem aos leitores termos para uso em buscas de documentos similares na web;

3. auxiliam indexadores e editores a agrupar materiais relacionados;

4. permitem que editores e pesquisadores registrem mudanças nos assuntos de uma disciplina através do tempo;

5. ligam tópicos específicos de pesquisa dentro de um escopo maior (HARTLEY; KOSTOFF, 2003, apud LIMA GONÇALVES, 2008, p. 06).
}

Assim, realizaram-se a identificação e a quantificação das dez palavras-chave mais utilizadas nas dissertações e teses sintetizadas no quadro e chegou-se ao seguinte resultado: (24) Assistência Estudantil; (12) Educação Superior/Ensino Superior; (09) Permanência/ Permanência Estudantil; (06) Política Educacional/Políticas Educacionais; (06) Política de Assistência Estudantil; (05) Educação; (05) Ação Afirmativa/Ações Afirmativas; (05) Pnaes; (03) Política Pública; (02) Política Social.

Com a análise das palavras-chave, notou-se, então, que as palavras utilizadas demonstraram vínculo direto com o título, permitindo, assim, um contexto identificável ao leitor. De certo, a partir dessas palavras, foi possível estabelecer a relação relevante do 
material encontrado com os interesses da pesquisa, assim como foram fundamentais para localização e mapeamento dos estudos da temática.

Feita a análise dos títulos e palavras-chave, teve-se novamente a possibilidade de ratificar a legitimidade do quadro síntese do mapeamento da temática Política de Assistência Estudantil no âmbito do Pnaes, dado que todas as abordagens tratam da questão da Assistência Estudantil no contexto do Pnaes. Então, passou-se à leitura dos resumos dos trabalhos que atenderam a todos os filtros estabelecidos na pesquisa.

\section{ANÁLISE DAS TESES E DISSERTAÇÕES: ACHADOS E REPERCUSSÕES}

Ao ler os 36 resumos, notou-se, a priori, que os estudos selecionados dispunham de relevantes produções no campo da Educação, a considerar que suas abordagens apontavam para diversas perspectivas de análise da Política de Assistência Estudantil brasileira na educação superior. Em razão da extensa quantidade mapeada e selecionada, optou-se por apresentar uma síntese descritiva das pesquisas por cada ano correspondente. A escolha deu-se de modo aleatório com auxílio de uma ferramenta online ${ }^{6}$, cujo resultado encontra-se no quadro a seguir:

Quadro 4 - Pesquisas selecionadas para realização da síntese descritiva7

\begin{tabular}{|c|l|l|l|}
\hline Ano & \multicolumn{1}{|c|}{ Autor (a) } & \multicolumn{1}{c|}{ Título } & \multicolumn{1}{c|}{ Programa/IES } \\
\hline 2019 & $\begin{array}{l}\text { SILVA, Adão Rogerio } \\
\text { Xavier }\end{array}$ & $\begin{array}{l}\text { A materialização do Programa Nacional } \\
\text { de Assistência Estudantil na } \\
\text { Universidade Federal do Acre: texto, } \\
\text { contexto, processos e práticas }\end{array}$ & $\begin{array}{l}\text { Programa de Pós- } \\
\text { Graduação em } \\
\text { Educação da } \\
\text { Universidade Federal } \\
\text { do Acre }\end{array}$ \\
\hline 2018 & $\begin{array}{l}\text { SANTOS, Elenice Cheis } \\
\text { dos }\end{array}$ & $\begin{array}{l}\text { Política de Assistência Estudantil para } \\
\text { estudantes cotistas de baixa renda na } \\
\text { Universidade Federal do Rio Grande do } \\
\text { Sul - UFRGS }\end{array}$ & $\begin{array}{l}\text { Programa de Pós- } \\
\text { Graduação em } \\
\text { Educação da } \\
\text { Universidade Federal } \\
\text { do Rio Grande do Sul }\end{array}$ \\
\hline MOTTA, Thalita Cunha & $\begin{array}{l}\text { Assistência estudantil e inclusão social: } \\
\text { mudanças discursivas e } \\
\text { recontextualização no caso do IFRN }\end{array}$ & $\begin{array}{l}\text { Programa de Pós- } \\
\text { Graduação em } \\
\text { Educação da }\end{array}$ \\
\hline
\end{tabular}

\footnotetext{
${ }^{6}$ Ferramenta utilizada para sorteio aleatório https://sorteador.com.br/sorteador/numeros.

7 Observa-se, nos resultados do mapeamento (Quadro 3 e 4), que a maioria das pesquisas são voltadas a estudos de casos em instituições específicas, sob esse efeito, e considerando o percurso metodológico aqui empreendido, infere-se existir uma carência de estudos que se reportem à situação da Política de Assistência Estudantil no plano nacional.
} 
REVISTA

PEDA

Revista do Programa de Pós-Graduação em Educação da Unochapecó

ISSN 1984-1566 (on-line) ISSN 1415-8175 (impressa)

\begin{tabular}{|c|c|c|c|}
\hline & & & $\begin{array}{l}\text { Universidade Federal } \\
\text { de Pernambuco }\end{array}$ \\
\hline 2016 & LEAL, Elisiene Borges & $\begin{array}{l}\text { Vozes afrodescendentes: o que alguns } \\
\text { (mas) estudantes da Universidade } \\
\text { Federal do Piauí contam sobre a } \\
\text { assistência estudantil? }\end{array}$ & $\begin{array}{l}\text { Programa de Pós- } \\
\text { Graduação em } \\
\text { Educação da } \\
\text { Universidade Federal } \\
\text { do Piauí }\end{array}$ \\
\hline 2015 & LOEBLIN, Elaine Lucio & $\begin{array}{l}\text { A materialização do Programa Nacional } \\
\text { de Assistência Estudantil PNAES para } \\
\text { estudantes de graduação da UNIR/ Ji- } \\
\text { paraná/RO }\end{array}$ & $\begin{array}{l}\text { Programa de Pós- } \\
\text { Graduação em } \\
\text { Educação da } \\
\text { Universidade Federal } \\
\text { de Mato Grosso } \\
\text { Universidade Federal } \\
\text { de Rondônia }\end{array}$ \\
\hline 2014 & $\begin{array}{l}\text { SANTIAGO, Salomão } \\
\text { Nunes }\end{array}$ & $\begin{array}{l}\text { A política de assistência estudantil no } \\
\text { governo Lula: } 2003 \text { a } 2010\end{array}$ & $\begin{array}{l}\text { Programa de Pós- } \\
\text { Graduação em } \\
\text { Educação, do Instituto } \\
\text { de Ciências da } \\
\text { Educação da } \\
\text { Universidade Federal } \\
\text { do Pará }\end{array}$ \\
\hline 2013 & $\begin{array}{l}\text { RADAELLI, Andressa } \\
\text { Benvenutti }\end{array}$ & $\begin{array}{l}\text { Permanência na Educação Superior: } \\
\text { uma análise das Políticas de Assistência } \\
\text { Estudantil na Universidade Federal da } \\
\text { Fronteira Sul }\end{array}$ & $\begin{array}{l}\text { Programa de Pós- } \\
\text { Graduação em } \\
\text { Educação da } \\
\text { Universidade Estadual } \\
\text { do Oeste do Paraná }\end{array}$ \\
\hline
\end{tabular}

Fonte: Quadro elaborado pelos autores (2020).

Feita essa seleção, antes de seguir às sínteses descritivas, buscou-se, por conseguinte, dar uma dimensão mais ampla acerca dos tipos e características de pesquisas empreendidas nos estudos selecionados. Assim, a partir do embasamento em Gil (2008), criou-se um quadro comparativo quanto às finalidades, aos níveis, às abordagens, aos procedimentos, aos instrumentos e ao recorte temporal dos estudos.

Quadro 5 - Quadro comparativo dos tipos e características das pesquisas

\begin{tabular}{|c|c|c|c|c|c|c|}
\hline & \multicolumn{3}{|c|}{ Tipo de pesquisa } & \multicolumn{3}{|c|}{ Características das pesquisas } \\
\hline Autor (a) & Finalidade & Nível & Abordagem & $\begin{array}{c}\text { Procedimento } \\
\text { S }\end{array}$ & Instrumentos & $\begin{array}{c}\text { Recorte } \\
\text { tempora } \\
\text { I }\end{array}$ \\
\hline $\begin{array}{l}\text { XAVIER } \\
\text { SILVA } \\
(2019)\end{array}$ & Pura & $\begin{array}{l}\text { Exp } \\
\text { lora } \\
\text { tóri } \\
\text { a } \\
\text { Exp } \\
\text { lica } \\
\text { tiva }\end{array}$ & $\begin{array}{c}\text { Qualitativa } \\
\text { Quantitati } \\
\text { va }\end{array}$ & $\begin{array}{l}1 \text { - Bibliográfico } \\
2 \text { - Documental } \\
3 \text { - Estudo de } \\
\text { caso }\end{array}$ & $\begin{array}{l}\mathbf{1} \text { - Teses, } \\
\text { dissertações e } \\
\text { artigos; } \\
\text { 2 - Leis, resoluções, } \\
\text { normativas etc.; } \\
\text { 3 - Universidade } \\
\text { Federal do Acre, } \\
\text { campus Sede. }\end{array}$ & $\begin{array}{l}2013- \\
2017\end{array}$ \\
\hline
\end{tabular}


REVISTA

Revista do Programa de Pós-Graduação em Educação da Unochapecó ISSN 1984-1566 (on-line) ISSN 1415-8175 (impressa)

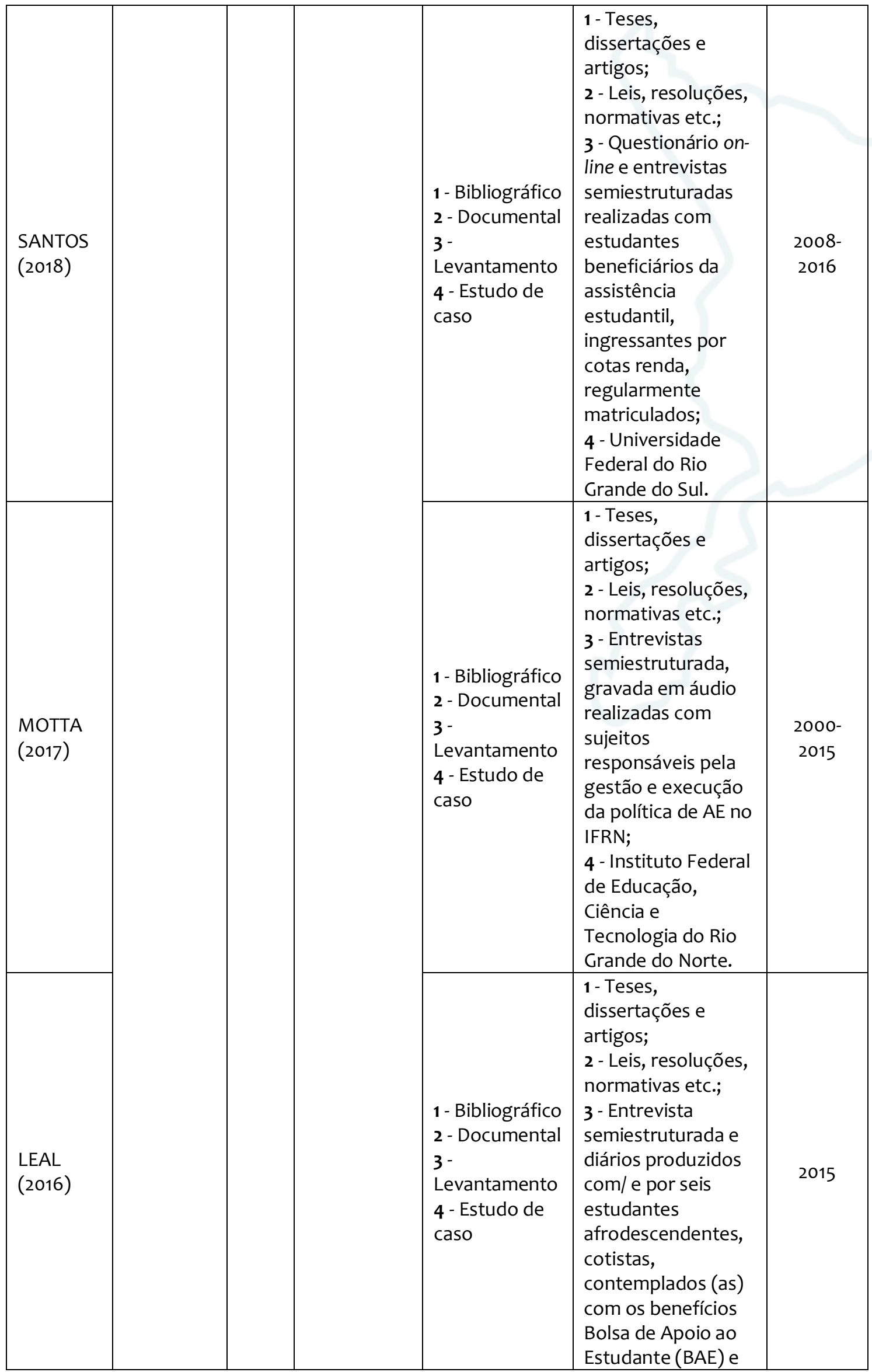


Revista do Programa de Pós-Graduação em Educação da Unochapecó ISSN 1984-1566 (on-line) ISSN 1415-8175 (impressa)

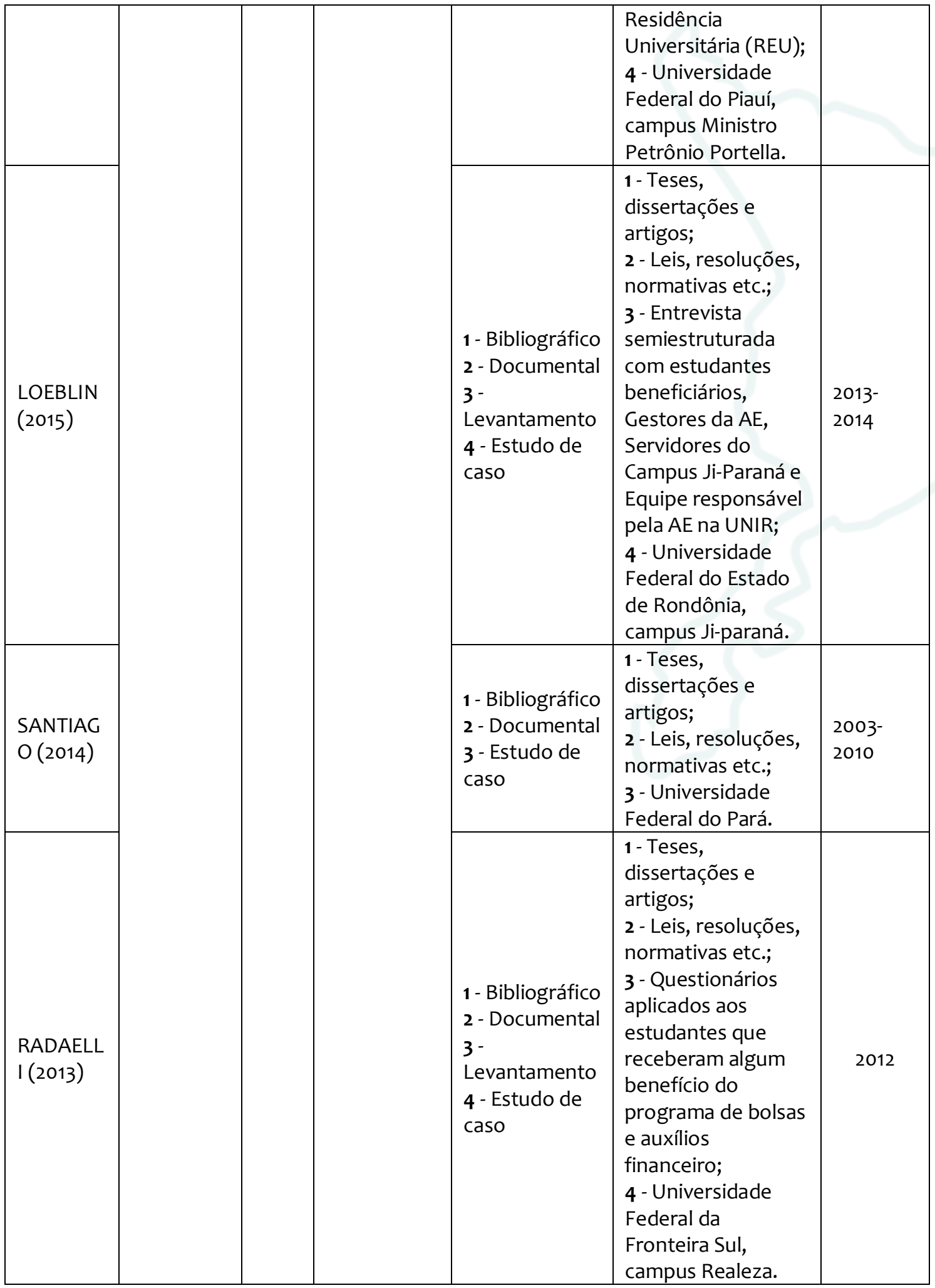

Fonte: Quadro elaborado pelos autores (2020).

Silva (2019) presta-se a analisar a materialização da Política de Assistência Estudantil (PAE) na Universidade Federal do Acre, considerando o contexto de execução do 


\section{REVISTA}

\section{Revista do Programa de Pós-Graduação em Educação da Unochapecó}

ISSN 1984-1566 (on-line) ISSN 1415-8175 (impressa)

Programa Nacional de Assistência Estudantil no período de 2013 a 2017, tomando como base de orientação a questão geral: Como tem se materializado, no Campus Sede da Ufac, a Política de Assistência Estudantil (PAE)?

Para isso, utilizou-se do aporte teórico-metodológico da abordagem do ciclo de políticas de Bowe et al. (1992) e Ball (1994), a partir da interlocução com Mainardes (2006, 2009, 2018), Mainardes e Marcondes (2009) e Mainardes e Stremel (2015), levando em consideração os contextos de influência, produção do texto e da prática. E, ainda, como base analítica da PAE, ancorou-se nas categorias teóricas e definições conceituais formuladas por Nascimento (2012), Kowalski (2012), Leite (2012), e Sguissardi (2014). O estudo teve como coleta de dados pesquisas bibliográficas e pesquisa documental.

Como resultados, o autor discorre que a materialização da PAE, no contexto do Pnaes, ocorreu em duas fases distintas na Ufac, sendo a primeira entre os anos de 2008 e 2012, quando a PAE foi executada e gerenciada por diferentes unidades administrativas. Por sua vez, a segunda fase deu-se a partir de 2013 até os dias atuais, cujo marco inaugural é a criação e atuação de órgão responsável pelo planejamento e execução, a Pró-Reitoria de Assuntos Estudantis (Proaes). Nessa última fase, Silva (2019) expõe que houve uma ampliação quantitativa e diversificação das ações/programas de assistência estudantil na Ufac, bem como um maior aporte financeiro ao subsídio do Restaurante Universitário (RU).

O autor identifica como a materialização da PAE, no contexto investigado, dá-se de uma forma mista, em que o atendimento é pautado pela lógica da inclusão/exclusão devido à focalização e seletividade dos perfis. Expõe, ainda, os programas Pró-Estudo e PróInclusão, Passe Livre, como auxílio, e o subsídio ao RU, como ações de maior abrangência na graduação e equilíbrio entre licenciaturas e bacharelados, extensivos aos cursos mais seletivos da Ufac, como as engenharias e a medicina. Isso posto, considera que a atual configuração das ações contribui para reconhecer a relevância da PAE como conjunto de condições articuladas para assegurar a permanência dos estudantes nos cursos de graduação da instituição.

Santos (2018) propõe-se a identificar e analisar em que medida a Política de Assistência Estudantil impacta na Política de Ação Afirmativa para estudantes de baixa renda, autodeclarados (ou não) pretos, pardos, ou indígenas, egressos de escola pública, na Universidade Federal do Rio Grande do Sul. A autora busca responder se a instituição 


\section{REVISTA}

está garantindo a inclusão de seus estudantes cotistas ingressantes por baixa renda, sob a ótica da justiça social e da equidade, através das ações oferecidas pela Política de Assistência Estudantil.

Para tanto, apoia-se em uma reflexão crítica de acesso à política educacional, com base no princípio da equidade e democratização do ensino público, à luz do referencial teórico da Justiça Social Bidimensional como redistribuição socioeconômica e reconhecimento cultural, de Frase (2006), das noções de Justiça/Injustiças, de Bourdieu (1996; 1997; 1998), de Justiça Social como equidade, de John Rawls (2008), e da Justiça Social como reconhecimento, de Axel Honneth (2003). Metodologicamente, a pesquisa é conduzida por aspectos quantitativos e qualitativos, incluindo elementos bibliográficos, documentais, analíticos, questionários virtuais e entrevistas. A interpretação dos dados oriundos dos questionários virtuais e das entrevistas foi realizada com auxílio de gráficos e da técnica de análise de conteúdo, considerando duas categorias: o Acesso, na perspectiva da inclusão/exclusão, e a Permanência, na perspectiva da Assistência Estudantil.

Nos resultados finais, a autora destaca que os indivíduos que perseguem a inserção na educação superior por via das políticas que se apresentam como inclusivas vivenciam processos de exclusão na luta pela sua permanência na universidade. Desse modo, ainda que a proposta de ampliação do acesso com a democratização do Ensino Superior tenha avançado na oferta aos estudantes menos favorecidos, não há ampliação, nas mesmas proporções, do incentivo à política de permanência que atenda a esta nova demanda.

Nesse sentido, a autora infere que, diante do modelo preconizado de Justiça Social Bidimensional de reconhecimento e redistribuição para a educação superior, e das especificidades socioeconômicas da maioria dos estudantes que buscam vaga no Ensino Superior, a efetividade da $A E$, enquanto política pública que visa à permanência, torna-se uma exigência para a democratização e para a qualidade da educação.

Motta (2017) apresenta, em sua tese, o estudo de caso sobre a Política de Assistência Estudantil (PAE) do Instituto Federal de Educação, Ciência e Tecnologia do Rio Grande do Norte (IFRN). Propõe, como objetivo geral, analisar os discursos da política de AE do IFRN nos processos de transformação institucional e da política educa cional, e busca responder a seguinte questão: Que discursos são predominantes na política de AE do IFRN, considerando os processos de transformação institucional e da política educacional? 


\section{REVISTA}

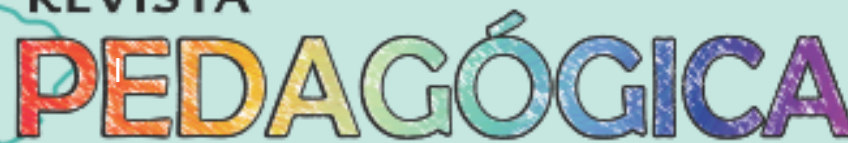

\section{Revista do Programa de Pós-Graduação em Educação da Unochapecó ISSN 1984-1566 (on-line) ISSN 1415-8175 (impressa)}

Para tanto, volta-se para análise documental, observações e entrevista. Adota, como aportes teórico-metodológicos, a abordagem do ciclo de políticas de Ball e a Análise do Discurso Crítica de Norman Fairclough. Na análise, a autora considera que o Pnaes facilitou o reconhecimento da Assistência Estudantil enquanto política educacional no IFRN e auxiliou na formalização de critérios de atendimento prioritário aos estudantes mais vulneráveis. Por outro lado, dada a especificidade do arcabouço formal do Pnaes, que se direciona ao atendimento de estudantes matriculados no Ensino Superior público federal, ficou evidente a dificuldade de atendimento ao público de nível médio e técnico do IF.

Os discursos analisados no IFRN acerca da PAE demonstraram o desejo de rompimento das concepções assistencialistas da Assistência Estudantil, advindas da origem da instituição, ainda quando Escola de Aprendizes Artífices, fundada em 1909 e instalada inicialmente em 1910 em Natal (RN). Conforme a autora, o conjunto de ações, como a política de cotas, a expansão da instituição e o Pnaes, possibilitou ao IFRN avançar em prol da defesa da $\mathrm{AE}$ como um direito estudantil, sob um ângulo de inclusão sociodemocrática, visto que os dados aferidos indicam a ampliação do acesso de estudantes das classes populares e das ações de apoio à permanência estudantil. Nessa direção, a lógica operacional do conjunto dessas ações, sobretudo do Pnaes, refletiu na predominância da perspectiva focalizada de atendimento aos estudantes mais vulneráveis, a partir dos programas de auxílios financeiros.

Contudo, em seu entendimento amplificado, "a política de AE do IFRN segue o modelo de coexistência de atendimento universalista e focalista" (MOTTA, 2017, p. 09), dado que, dentre os 12 grupos de ações de AE desenvolvidas entre os anos de 2009 e 2015, apenas 03 são ações que focalizam o atendimento de estudantes em vulnerabilidade (bolsa de auxílio transporte, bolsa de iniciação profissional, bolsa de auxílio alimentação). As demais ações de AE são consideradas do tipo de atendimento universalizado, a exemplo da bolsa Proeja, que é universalizada para os estudantes do programa, e as bolsas acadêmicas, cujos critérios de seleção se atêm a quesitos meritocráticos.

Assim sendo, a tese defendida por Motta (2017) assinala que a perspectiva prática universalista e focalista da $A E$ no IFRN pode ser estratégia de efetivação do direito à educação, em um contexto de graves desigualdades. Logo, tem-se a articulação da AE com as proposições político-pedagógicas da formação completa dos estudantes, na direção de 
uma recontextualização e de mudanças discursivas em relação à inclusão sociodemocrática.

Leal (2016) lança-se na pesquisa para compreender a importância das ações afirmativas efetivadas no âmbito da Pró-Reitoria de Assuntos Estudantis e Comunitários (PRAEC) da Universidade Federal do Piauí (UFPI), tomando como perspectiva a concepção de estudantes afrodescendentes, cotistas, assistidos pela Bolsa de Apoio ao Estudante (BAE) e pela Residência Universitária (REU).

O objetivo é identificar aspectos do perfil dos(as) estudantes selecionados(as) e conhecer algumas de suas experiências em relação aos dois benefícios, suas dificuldades de acesso ao Ensino Superior, o que esperam e o que pensam a respeito das ações implementadas pela PRAEC/UFPI. Para tanto, traz como questão central: Quais são as dificuldades que eles(as) enfrentam, o que eles(as) esperam da assistência estudantil na UFPI e o que pensam diante de suas vivências a respeito dos serviços oferecidos pela Pró Reitoria de Assuntos Estudantis e Comunitários (PRAEC)? Adota, na investigação, uma abordagem qualitativa-quantitativa e toma, como instrumentos de acesso aos dados, entrevistas semiestruturadas, análise de documentos e pesquisas estatísticas.

Utiliza como referências teóricas autores(as) como: Boakari (2003,2013); Cunha Júnior (2005); Gomes (2012); Olive (2002); Silvério (2003, 2007), Silva (2003); Romanelli (2009) e outros(as). Conforme a autora, a análise de dados permitiu uma reflexão sobre as implicações de ser estudante universitário(a) afrodescendente, especialmente no que tange às desigualdades sociais e raciais latentes na sociedade brasileira. Assim, o contexto da vida acadêmica experienciada por esse aluno é permeado de discriminações e exclusões, tais como "brincadeiras" e piadinhas por conta dos seus fenótipos.

No que se refere às ações de $A E$ oferecidas aos estudantes afrodescendentes da UFPI, são fundamentais para permanência e conclusão do Ensino Superior, dada a realidade socioeconômica precária destes. Das experiências vivenciadas por tais estudantes, descobriu-se que o fator econômico é um aspecto preocupante, visto que os recursos previdentes da $\mathrm{AE}$ não cobrem todos os gastos básicos para manutenção da vida estudantil, tais como transporte, alimentação, moradia, necessidades básicas como aquisição de livros, apostilas, cadernos, vestimentas, saúde, higiene pessoal, alimentação. 
Loeblin (2015) investiga a materialização do Pnaes na Universidade Federal de Rondônia, especificamente, no campus localizado na cidade de Ji-Paraná, a fim de verificar em que medida essa política contribui para o processo de permanência e conclusão dos estudantes de graduação assistidos na instituição. Desse modo, procura identificar como ocorre a operacionalização da AE no campus, quais são seus avanços, limites e desafios. Sua pesquisa configura-se como bibliográfica, documental e de campo, sob perspectiva teórico-empírica do materialismo histórico-dialético.

A autora considera que o Pnaes é marcado pelas relações da reestruturação produtiva do mundo do trabalho, em que as políticas neoliberais se fazem presentes e causam fortes interposições nas políticas públicas e, em especial, na educação. Logo, sua legitimação é parte das estratégias dos organismos multilaterais para a educação no Brasil. Resulta da análise realizada pela pesquisadora que as ações de AE voltadas para os estudantes em situação de vulnerabilidade socioeconômica no campus de Ji-Paraná são recentes, iniciadas a partir da instituição do Pnaes pela Portaria $n^{\circ}$ 39/2007. Nesse contexto, os dados examinados, a partir de amostra de 234 estudantes assistidos por ações de AE no ano de 2013, apontam que a evasão (matrículas trancadas) representa 5,5\%; por outro lado, o insucesso acadêmico (débito de disciplinas referente ao período do curso em que se encontram matriculados) reflete $53 \%$.

A pesquisa traz, também, a compreensão dos estudantes e servidores sobre as ações de $A E$ na instituição, e verifica-se que a percepção destes é a de que as ações imprimem características de política focalizada, seletista, que visa a garantir os mínimos necessários aos estudantes assistidos. Assim, dentre os vários limites e desafios tem-se o fato de tornar-se uma política universalista, buscando superar a sua dimensão atual, bem como a ampliação urgente do monitoramento e acompanhamento das ações.

Santiago (2014) investiga a Política de Assistência Estudantil composta no período do governo Lula (2003-2010) para o atendimento dos estudantes de graduação das IFES, em específico, da Universidade Federal do Pará (UFPA), visando a identificar sua repercussão no que se refere à permanência dos estudantes. Assim, toma como indagação central a questão: Como tem se desenvolvido a Política de Assistência Estudantil no contexto da política de acesso e permanência na Ifes durante o governo Lula (2003-2010)? 
Com esse objetivo, utiliza-se da pesquisa bibliográfica e documental a partir do referencial teórico do materialismo histórico, com as categorias da contradição e mediação, analisa leis e decretos afetos, dados estatísticos e orçamentários da expansão do Ensino Superior, em especial, os da UFPA, para responder a supracitada questão. Utiliza, ainda, a categoria de permanência relacionada à Política de Assistência Estudantil.

O autor considera que compreender esse processo pressupõe partir da consideração do contexto da crise estrutural do capital, sobretudo, de quando, no plano político e econômico, os ideais do neoliberalismo ganham força. Daí se tem a reestruturação produtiva e a redefinição do papel do Estado e das políticas sociais, dentre as quais encontra-se a assistência estudantil. Verifica-se, na sua conclusão, que a assistência estudantil institucionalizada por meio do Pnaes apresenta uma concepção limitada, fragmentada e focalizada nos segmentos sociais mais empobrecidos, em um cenário em que prevalece a lógica do menor recurso orçamentário para o maior quantitativo de atendimento, o que subtrai da AE seu caráter de direito social universal. Nesses termos, considera que essa lógica repercute de modo relativamente negativo na permanência dos estudantes na UFPA, consequentemente, isso incide diretamente no insucesso na conclusão dos cursos.

Radaelli (2013) examina a assistência estudantil na educação superior pública considerando a experiência da Universidade Federal da Fronteira Sul (UFFS). Assim, revisa pontos centrais do processo de expansão através do Programa de Apoio a Planos de Reestruturação e Expansão das Universidades Federais (Reuni), e do dispositivo de incentivo à permanência, o Programa Nacional de Assistência Estudantil (Pnaes), a fim de compreender a dinâmica do acesso e a permanência do estudante in loco.

A autora utiliza-se da pesquisa bibliográfica, documental e de questionários aplicados aos estudantes atendidos pelo programa de bolsa e auxílios desenvolvidos no ano de 2012 pela UFFS - Campus Realeza. Nesse contexto, resulta dos dados analisados que a expansão do acesso ao Ensino Superior não convém ser conduzida somente pela garantia do ingresso na universidade, mas, também, tem-se que gerar condições de permanência para o estudante no trajeto universitário.

Desse modo, as ações desenvolvidas nesse sentido incidem na configuração de programas que ofertam bolsas e auxílios financeiros para subsidiar despesas vitais, tais 
como moradia, alimentação e transporte. Estas são ações essenciais para a manutenção da permanência e conclusão da graduação. A autora salienta, ainda, que o processo de reformas da educação superior implementado no Brasil, especialmente no âmbito do Reuni, porta objetivos ideológicos, ações e contradições estabelecidas em relação aos pressupostos teóricos e práticos que, simultaneamente, resultam na reforma do Estado e procuram dar sustentação aos interesses sociais.

Os estudos mapeados e selecionados acima tornam-se suporte à compreensão da conceituação da Política de Assistência Estudantil no contexto do Pnaes, na medida em que proporcionaram um paralelo de análise entre suas respostas de pesquisa e a concepção teórica da assistência estudantil.

Sobre a natureza teórica das Políticas de Assistência Estudantil, Nascimento (2012, p. 147) aponta que esse cuidado, quando não desenvolvido, "colocam-se como entraves à delimitação das políticas de assistência ao estudante. A fragilidade da definição do que é assistência estudantil - a qual assistência nos referimos, visto que é desenvolvida no âmbito da educação". Segundo a autora, parece haver equívocos de ordem teórica nas agendas políticas da assistência ao estudante, sendo estes:

1. O entendimento da assistência estudantil como sendo extensão das ações da Política de Assistência Social, o que leva as instituições de ensino a tentarem definir as ações de assistência ao estudante sob as bases da assistência social, enquanto política específica, e 2. A restrição do conceito de necessidades, quando se trata das necessidades estudantis - sua redução ao plano das necessidades de sobrevivência (NASCIMENTO, 2012, p. 147).

Faz-se necessário reconhecer que a dimensão assistencial na Política de Assistência Estudantil - teoricamente - possui especificidade própria, logo, a sua dimensão assistencial não se configura na perspectiva de extensão das bases da assistência social como política específica, visto que, historicamente, a dimensão assistencial das políticas sociais brasileiras estiveram expressas nas dimensões emergencial e focalizada, infundindo-as a “[...] um perfil limitado e ambíguo: se apoiam muitas vezes, na matriz do favor, do apadrinhamento, do clientelismo e do mando, formas enraizadas na cultura política do país" (YASBEK, 1993, p. 50, apud NASCIMENTO, 2012, p. 149). Logo, a lógica estruturada baseada nessa perspectiva assistencial distancia-se da perspectiva do direito social. 
Considerando, ainda, que os procedimentos assistenciais manifestos nas políticas sociais “[...] revela-se, ao mesmo tempo, como exclusão e inclusão dos bens e serviços prestados direta ou indiretamente pelo Estado" (SPOSATI et al, 2008, p. 30 apud NASCIMENTO, 2012a, p. 149), os sentidos dessa perspectiva assistencial reflete duas faces: sendo a primeira a de inclusão, por atender às necessidades concretas dos estudantes e, a segunda, de exclusão, por conceber critérios de elegibilidades, de focalização, de seletividade, conforme o movimento de reorientação das políticas públicas sociais pautadas a partir década de 1990 (NASCIMENTO, 2012).

Nesse sentido, é importante sinalizar que a face de exclusão

[...] é reafirmada no entendimento das políticas assistenciais enquanto compensatórias de carência, o que legitima a função do Estado em selecionar o grau de carência da demanda, além de oferecer serviços de baixa qualidade, já que, nessa perspectiva, os serviços públicos se destinam a uma população dita carente e minoritária. Por isso são prestados em condições precárias quantitativa e qualitativamente [...] a implementação de uma Política de Assistência Estudantil reduzida a benefícios focalizados, emergenciais, destinados a um público específico, é fruto da forma como se configurou o assistencial, no Brasil, nos limites da formação social do país. Por isso, é importante enfatizar que a focalização, a seletividade e o caráter emergencial não são características próprias à Política de Assistência Social, está também incorpora tais diretrizes, pelo mesmo motivo das demais políticas sociais de caráter assistencial (NASCIMENTO, 2012, p. 149-151).

Do exposto até aqui, pode-se dizer, então, que, do ponto de vista teórico, a configuração assistencial na Política de Assistência Estudantil deve(ria) ser interpretada somente como transversal, dada a sua configuração de política social que perpassa as ações assistenciais promovidas pelo Estado, e que se propõe a assistir uma necessidade.

Considerando que as políticas sociais possuem uma dimensão assistencial, afirmamos que a assistência estudantil, no âmbito da educação superior, manifesta o próprio caráter assistencial da Política de Educação. Essas ações surgem, no espaço universitário, a partir das reivindicações dos movimentos sociais organizados em defesa do provimento, pelas instituições educacionais e Estado, das condições materiais e imateriais necessárias à permanência dos estudantes nessa modalidade de ensino (NASCIMENTO, 2012, p. 149).

Compreender essa questão torna-se fundamental para o entendimento teórico de que a Política de Assistência Estudantil possui característica própria, e que não se deve compreendê-la como sendo inerente a uma extensão da Política de Assistência Social, pois 
A presença histórica de ações assistenciais do Estado na educação exprime a vinculação da assistência estudantil com as políticas educacionais, destacando, portanto, o seu caráter autônomo da Assistência social enquanto política específica [...] assistência estudantil não está vinculada à Política de Assistência Social e, portanto, não se submete aos preceitos de sua regulamentação, devendo, sim, ser entendida enquanto política educa cional - uma vez que se trata de ações de cunho assistencial desenvolvidas no âmbito da educação (NASCIMENTO, 2012, p. 151 -152)

Tratando-se do segundo ponto, que versa sobre a restrição do conceito de necessidades, quando se refere às necessidades estudantis, na medida em que se tem

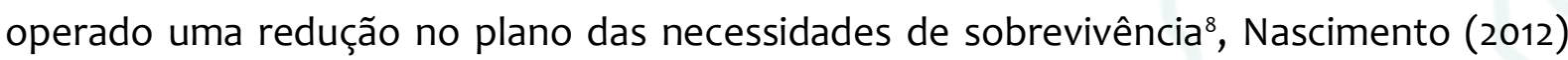
explicita que,

\begin{abstract}
Se tomarmos como exemplo os Programas de Moradia Estudantil, fica possível perceber a importância da leitura crítica das necessidades estudantis na formulação das ações de assistência a esse público específico. Uma peculiaridade desses Programas é o fato de exigirem articulação com as demais políticas desenvolvidas no espaço universitário, pois, se levarmos em consideração a complexidade das necessidades estudantis, veremos que a convivência nas Casas de Estudantes desencadeia uma série de outras demandas que são fruto da especificidade das condições de vida dos estudantes e, portanto, extrapolam a demanda por moradia, se esta for entendida enquanto teto somente. [...] mesmo sendo a centralidade do programa prover a moradia, não há como ignorar a existência de outras demandas que envolvem "o morar" (NASCIMENTO, 2012, p. $152-154)$.
\end{abstract}

A referida autora considera, ainda, que só será possível ter um cenário abrangente dos programas de assistência estudantil se as diretrizes destes se pautarem nas reais necessidades dos estudantes, o que requer nova interpretação do conceito de necessidades, isto é, uma leitura crítica das necessidades que tome como ponto de partida a condição social e a realidade social na qual esses estudantes estão inseridos. E que, assim, ultrapasse a dimensão biológica das necessidades estudantis, de modo que contribua teórico-metodologicamente com a estruturação dos programas da assistência estudantil

\footnotetext{
${ }^{8}$ Nascimento (2012), utilizando-se da concepção teórica baseada em Pereira (2008), discorre que o conceito de necessidades naturais, vitais ou de sobrevivência, surgiu como sinônimo de necessidades básicas, identificada por uma dimensão biológica e de tal modo "[...] em nada se diferenciam das necessidades animais e, portanto, não exigiam para o seu atendimento nada mais do que um mínimo de satisfação" (PEREIRA, 2008, p. 58, apud NASCIMENTO, 2012, p. 152).
} 
em coerência com sua finalidade integral, qual seja, reduzir as desigualdades educacionais (NASCIMENTO, 2012).

Nesse sentido, é imprescindível salientar que os programas de assistência estudantil são políticas sociais distintas, com regulamentações e objetivos próprios. Logo, faz-se necessário levar em consideração a conjuntura e o cenário social vigente educacional de sua materialização, de modo a possibilitar que se desenvolvam programas e ações com um escopo específico, cujo vínculo de produção, prática, resultados e avaliação estejam totalmente integrados à comunidade acadêmica (docentes, discentes e técnicos administrativos).

Assim, a formulação dessa política perpassa totalmente as perspectivas e compreensão acerca do que seriam condições de permanência, isto é, um entendimento de quais seriam as necessidades factuais dos estudantes para continuarem os percursos das suas formações acadêmicas, bem como a conectividades com as reais estruturas das Ifes e atuações dos demais membros da comunidade acadêmica.

\section{CONSIDERAÇÕES FINAIS}

Ao se traçar um paralelo entre os estudos mapeados, selecionados e descritos e a concepção teórica da Assistência Estudantil, em específico, a análise comparativa entre os resultados aferidos nos estudos e os equívocos teóricos manifestos nas agendas das políticas da assistência ao estudante permite perceber marcas proporcionais em ambas as perspectivas teóricas. Isto é, em maior ou menor medida, manifesta-se ou como extensão das Política de Assistência Social9 (aos moldes de como define YASBEK (1993) ou como necessidade de sobrevivência ${ }^{10}$.

\footnotetext{
9 "Os resultados da pesquisa apresentam dados qualitativos e quantitativos relativos às políticas de acesso e permanência na Universidade, e apontam que os mesmos sujeitos que anseiam por inserção na educação superior, através de políticas que se apresentam como inclusivas, vivenciam processos de exclusão na luta por sua permanência na Universidade. [...] não há ampliação, na mesma proporção, do incentivo a políticas de permanência que abarquem esta nova demanda" (SANTOS, 2018, p. 08).

${ }^{10}$ Com a política de cotas, a expansão institucional e o PNAES, o IFRN avançou em prol da defesa da AE como um direito estudantil, na perspectiva de uma inclusão sociodemocrática, uma vez que os dados demonstram ampliação do acesso de estudantes das classes populares e leque de ações de apoio à permanência estudantil. A complexificação da lógica operacional dessas ações refletiu na predominância da perspectiva focalizadora de atendimento aos mais vulneráveis nos programas de auxílios financeiros (MOTTA, 2017, p. 09).
} 
É importante lembrar que não se trata de negar que a Política de Assistência Estudantil em face do Pnaes representa um significativo avanço para o Ensino Superior, visto que tal política instituiu espaço para efetivação de políticas que ensejam o acesso e a permanência na educação superior, consoantes às especificidades educacionais do público-alvo beneficiário dessas políticas e das IES, em atenção ao compromisso com necessidades e demandas do segmento estudantil.

\begin{abstract}
Compreende a assistência estudantil as ações de cunho assistencial que são desenvolvidas no âmbito da política de educação e orientadas para o provimento das condições necessárias à permanência dos estudantes no ensino superior. Essas ações devem ser implementadas respeitando as particularidades estudantis, e considerando o contexto educacional brasileiro. Devem estar comprometidas com a ampliação da cobertura de seus serviços, tendo como norte a universalização do acesso (NASCIMENTO, 2012, p. 155).
\end{abstract}

Nesse sentido, manifesta-se a necessidade de estruturar as Políticas de Assistência Estudantil levando em consideração a conjuntura da educação superior, possibilitando, desse modo, que as ações assumam corpo próprio, estreitas ao campo da educação (NASCIMENTO, 2012).

Assim, considera-se que, em um cenário onde as materializações das ações das PAE ultrapassassem a lógica dos mínimos necessários, isto é, estabelecendo-se em um vínculo mais amplo em relação às especificidades conjunturais da educação superior, é admissível que sua efetividade tenderia a ser mais sólida e positiva. Isso não significa negar a atenção mais necessária, mas, também, não significa limitar-se somente a ela.

A discussão dessa temática é necessária, especialmente, frente ao cenário políticoeducacional em que se encontra o país, considerando a gestão do Governo Federal, cujo principal projeto apresentado à Educação Superior intitula-se (des) “Futura-se”, e traz, em sua concepção central, a diminuição da participação do Estado na manutenção financeira das IFES, encabeçando uma proposta de financiamento misto com a iniciativa privada e gestão compartilhada com Organizações Sociais (OSs). Certamente, algumas políticas públicas, dentre elas a Assistência Estudantil, estarão no centro de disputas e em risco de retração ou mesmo de extinção.

Desse modo, espera-se que este mapeamento e esta análise das produções científicas publicadas em teses e dissertações que versam sobre a temática "Políticas de 
Revista do Programa de Pós-Graduação em Educação da Unochapecó ISSN 1984-1566 (on-line) ISSN 1415-8175 (impressa)

Assistência Estudantil (PAE) no contexto do Programa Nacional de Assistência Estudantil (Pnaes)" colaborem com as arenas de disputas, a fim de que se possa fundamentar a continuidade, o melhoramento e expansão dessas políticas nos espaços da educação superior pública. Assim, reforça-se, neste estudo, que não se trata de negar as contribuições dos programas e ações materializados pelas IFES até então, contudo, não se pode perder de vista a necessária e constante revisão das PAE nas Ifes, isto é, que suas ações não se desloquem, sobretudo, das condições e das realidades sociais dos estudantes.

\section{REFERÊNCIAS}

ASSOCIAÇÃO BRASILEIRA DE NORMAS TÉCNICAS. NBR 6022 - Informação e documentação: artigo em publicação periódica impressa: apresentação. Rio de Janeiro, 2003. Disponível em: http://posticsenasp.ufsc.br/files/2014/04/abntnbr6022.pdf. Acesso em: 05 de mar. 2020.

BRASIL. Portaria Normativa $\mathbf{n}^{\circ}$ 39, de 12 dez. 2007. Institui o Programa Nacional de Assistência Estudantil - PNAES. Disponível em:

http://portal.mec.gov.br/arquivos/pdf/portaria_pnaes.pdf. Acesso em: 05 mar. 2020.

BRASIL. Decreto $\mathbf{n}^{\circ} \mathbf{7 . 2 3 4}$, de 19 de julho de 2010. Dispõe sobre o Programa Nacional de Assistência Estudantil - PNAES. Disponível em:

http://www.planalto.gov.br/ccivil_03/_Ato2007-2010/2010/Decreto/D7234.htm. Acesso em: 05 de mar. 2020.

COSTA, Simone Gomes. A equidade na educação superior: uma análise das Políticas de Assistência Estudantil. Dissertação (Mestrado em Sociologia) - Universidade Federal do Rio Grande do Sul, Porto Alegre, 2010.

FONAPRACE, Fórum Nacional de Pró-reitores de Assuntos Comunitários e Estudantis. Revista FONAPRACE: 20 Anos 1987-2007. Brasília, 2008.

GIL, Antonio Carlos. Métodos e técnicas de pesquisa social. 6. ed. São Paulo: Atlas, 2008.

KOWALSKI, Aline Viero. Os (des) caminhos da política de assistência estudantil e o desafio na garantia de direitos. 2012. 179 f. Tese (Doutorado em Serviço Social). Pontifícia Universidade Católica do Rio Grande do Sul - PUCRS, 2012.

LEAL, Elisiene Borges. Vozes afrodescendentes: o que alguns (mas) estudantes da Universidade Federal do Piauí contam sobre a assistência estudantil? Dissertação (Mestrado em Educação). Universidade Federal do Piauí - UFPI, 2016.

LIMA GONÇALVES, Aline. Uso de resumos e palavras-chave em Ciências Sociais: uma avaliação. Encontros Bibli: revista eletrônica de biblioteconomia e ciência da informação, v. 13, n. 26, s/p. 2008. 
Revista do Programa de Pós-Graduação em Educação da Unochapecó ISSN 1984-1566 (on-line) ISSN 1415-8175 (impressa)

LOEBLIN, Elaine Lucio. A materialização do Programa Nacional de Assistência Estudantil PNAES para estudantes de graduação da UNIR. Dissertação (Mestrado em Educação). Universidade Federal de Rondônia - UNIR, 2015.

MOTTA, Thalita Cunha. Assistência Estudantil e Inclusão Social. Tese (Doutorado em Educação). Universidade Federal de Pernambuco, UFPE, 2017.

NASCIMENTO, Clara Martins do. Elementos conceituais para pensar a política de assistência estudantil na atualidade. In: FONAPRACE; ANDIFES. (Org.). Revista Comemorativa 25 Anos do FONAPRACE: histórias, memórias e múltiplos olhares. 1. ed. Uberlândia: UFU PROEX, 2012.

PAULA, Maria de Fátima Costa de. Políticas de democratização da educação superior brasileira: limites e desafios para a próxima década. Avaliação: Revista da avaliação da Educação Superior, v. 22, p. 301-315, 2017.

RADAELLI, Andressa Benvenutti. Permanência na Educação Superior: uma análise das Políticas de Assistência Estudantil na Universidade Federal da Fronteira Sul. Dissertação (Mestrado em Educação). Universidade Estadual do Oeste do Paraná, UNIOESTE, 2013.

SANTIAGO, Salomão Nunes. A política de assistência estudantil no governo Lula: 2003 a 2010. Dissertação (Mestrado em Educação). Universidade Federal do Pará, UFPA, 2014.

SANTOS, Elenice Cheis dos. Política de assistência estudantil para estudantes cotistas de baixa renda na Universidade Federal do Rio Grande do Sul - UFRGS. 2018. Dissertação (Mestrado em Educação). Universidade Federal do Rio Grande do Sul, UFRGS, 2018.

XAVIER SILVA, Adão Rogério. A materialização do Programa Nacional de Assistência Estudantil na Universidade Federal do Acre: texto, contexto, processos e práticas. 2019. Dissertação (Mestrado em Educação). Universidade Federal do Acre - UFAC, 2019.

Enviado em: 28-05-2020

Aceito em: 27-10-2020

Publicado em: 01-02-2021 